\title{
IFN- $\gamma$ and IL-10 islet-antigen-specific T cell responses in autoantibody-negative first-degree relatives of patients with type 1 diabetes
}

\author{
L. G. Petrich de Marquesini - J. Fu • K. J. Connor • \\ A. J. Bishop • N. E. McLintock • C. Pope • F. S. Wong • \\ C. M. Dayan
}

Received: 14 December 2009/Accepted: 8 February 2010/Published online: 6 April 2010

(C) Springer-Verlag 2010

\begin{abstract}
Aims/hypothesis Islet antibody-negative first-degree relatives of type 1 diabetes patients have a very low risk of developing diabetes. We studied the balance between IFN- $\gamma$ (proinflammatory) and IL-10 (regulatory) T cell responses in these participants. Methods Peripheral blood T cells from adult (18-50 years old, $n=40) D R B 1^{*} 0401$-positive first-degree relatives negative for GAD and tyrosine phosphatase-like insulinoma antigen 2 (IA-2) antibodies were tested for IFN- $\gamma$ and IL-10 responses in a sensitive cytokine enzyme-linked immunospot assay against a panel of seven peptide epitopes derived from IA-2 and proinsulin. Comparison was made with HLAmatched newly diagnosed type 1 diabetic patients $(n=42)$ and healthy controls $(n=39)$.

Results First-degree relatives and newly diagnosed type 1 diabetic patients displayed a similar frequency of IFN- $\gamma$
\end{abstract}

L. G. Petrich de Marquesini · J. Fu • K. J. Connor • A. J. Bishop •

N. E. McLintock $\cdot$ C. M. Dayan $(\bowtie)$

Henry Wellcome Laboratory for Integrative Neuroscience

and Endocrinology, Dorothy Hodgkin Building,

Clinical Science at South Bristol, University of Bristol,

Whitson St,

Bristol BS1 3NY, UK

e-mail: Colin.Dayan@bristol.ac.uk

C. Pope $\cdot$ F. S. Wong

Department of Cellular and Molecular Medicine,

University of Bristol,

Bristol, UK

Present Address:

J. Fu

Department of Endocrinology,

Children's Hospital of Zhejiang University, School of Medicine,

Hangzhou, China responses to the peptide panel and both were significantly greater than in healthy controls (relatives $9.6 \%$, patients $11.8 \%$, controls $4.0 \%, p=0.003$ ). First-degree relatives and newly diagnosed type 1 diabetic patients also showed similar frequencies of IL-10 responses, which were significantly lower than in healthy controls (relatives $7.1 \%$, patients $9.0 \%$, controls $15.8 \%, p=0.003$ ). However, individual IL-10 responses of first-degree relatives were similar in size to those in healthy controls and larger than those in newly diagnosed type 1 diabetic patients (relatives median 29 spot-forming cells $/ 1 \times 10^{6}$ peripheral blood mononuclear cells, controls 33 , patients $11, p=0.02$ ).

Conclusions/interpretation Taken together, these results suggest that antibody-negative first-degree relatives have a balance of proinflammatory and regulatory $\mathrm{T}$ cells, which is intermediate between that of newly diagnosed type 1 diabetic patients and healthy controls. This suggests that even a moderate regulatory response may be sufficient to prevent the development of clinical type 1 diabetes in genetically predisposed individuals.

Keywords ELISPOT · First-degree relatives . Interferon-gamma $\cdot$ Interleukin-10 $\cdot$ Proinsulin $\cdot$ Regulatory $\mathrm{T}$ cells $\cdot \mathrm{T}$ cells $\cdot$ Type 1 diabetes

$\begin{array}{ll}\text { Abbreviations } \\ \text { CTLA-4 } & \text { Cytotoxic T-lymphocyte-associated protein } 4 \\ \text { ELISPOT } & \text { Enzyme-linked immunospot } \\ \text { IA-2 } & \text { Tyrosine phosphatase-like insulinoma antigen 2 } \\ \text { PBMC } & \text { Peripheral blood mononuclear cell } \\ \text { SFC } & \text { Spot-forming cells } \\ \text { Tregs } & \text { Regulatory T cells }\end{array}$




\section{Introduction}

It is now well established that the appearance of isletspecific autoantibodies in the blood predates the clinical onset of type 1 diabetes by many years [1]. This indicates that the autoimmune process in type 1 diabetes progresses rather slowly to beta cell destruction. Identification and modification of the factors involved in determining the speed of this process are major research goals, as they have the potential to delay development of hyperglycaemia and the need for insulin for many years, if not for the lifetime of the individual [2]. Studies of families with type 1 diabetes indicate that high-risk HLA-type, positive family history, an increasing number of different islet autoantibody specificities and younger age at appearance of autoantibodies are all associated with more rapid disease progression [1, 3-5].

In this context it is striking that first-degree relatives who have not developed islet autoantibodies by the age of 18 have a very low risk of ever developing diabetes, even though they may share $50 \%$ or more of the genetic risk and a large part of the environmental risk (by living in the same family) as their affected siblings, children or parents [6, 7]. The exact risk has not been computed as this would involve following a very large number of antibody-negative persons for a very long time, but the risk is sufficiently low for antibody-negative first-degree relatives to be excluded from follow-up in the TrialNet Natural History Study [8]. Similar observations have been made in studies of monozygotic twin pairs. Of 53 monozygotic twin pairs discordant for type 1 diabetes, only one of 31 initially antibody-negative twins $(3 \%)$ developed diabetes after a median follow-up of 12 years, despite being genetically identical to their diabetic co-twin, as compared with 11 of 22 antibody-positive twins $(50 \%)$ [9]. Taken together, these observations raise the possibility that first-degree relatives of patients with type 1 diabetes who remain antibody-negative into adulthood are in some way protected from developing type 1 diabetes.

Cell-mediated immunity involving $\mathrm{T}$ lymphocytes is believed to play the main role in causing the specific destruction of beta cells in type 1 diabetes [10]. Both CD4 and CD8 cells are involved [10]. However, in recent years it has become apparent that not all islet-specific $\mathrm{T}$ cells are proinflammatory and that populations exist, generally referred to as regulatory $\mathrm{T}$ cells (Tregs), which can actively protect against islet destruction [11]. In animal models, such populations include 'naturally occurring $\mathrm{T}$ regs' $\left(\mathrm{CD} 4^{+} \mathrm{CD} 25^{\mathrm{hi}}\right)$, which secrete TGF- $\beta$ [12] and have been shown to decline in numbers commensurate with the onset of diabetes in NOD mice [13]. In human type 1 diabetes, the role of naturally occurring Tregs is less well defined. Disruption of the FOXP3 gene, which is key to regulatory cell development, results in type 1 diabetes before the age of 1 year in a high frequency of boys with the IPEX syndrome [14]. However, although initial reports suggested a reduction in the number of $\mathrm{CD} 4{ }^{+} \mathrm{CD} 25^{+}$at diagnosis in type 1 diabetes [15], later studies have not confirmed this $[16,17]$. Increased levels of surface CD69 and intracellular cytotoxic T-lymphocyte-associated protein 4 (CTLA-4) have been reported in $\mathrm{CD} 4{ }^{+} \mathrm{CD} 25^{+} \mathrm{T}$ cells from newly diagnosed patients [18], but reduced levels of intracellular CTLA-4 have been reported in this T cell subset in 5-yearold children with strong genetic risk factors for diabetes [19].

Probably more relevant to an organ-specific autoimmune disease such as type 1 diabetes are the induced or adaptive Tregs. These cells are antigen-specific and develop from naive precursors in peripheral lymphoid organs after exposure to self-antigen. They include IL-10-secreting $\operatorname{Tr} 1$ cells and TGF- $\beta$ secreting Th3 cells. Such cells are induced by antigen-specific immunotherapy in animals [20,21] and in man [22, 23]. Moreover, at least in animals, they have been shown to effectively protect against disease. Although many techniques have been developed to detect antigenspecific $\mathrm{T}$ cell responses in humans [24], detection of circulating islet antigen-specific Tregs presents additional challenges. A recent study reported on a sensitive cytokine enzyme-linked immunospot (ELISPOT) assay, which is able to detect pro-inflammatory (IFN- $\gamma$-secreting) and potential regulatory (IL-10-secreting) $\mathrm{T}$ cells specific for a panel of peptides representing naturally processed and presented epitopes of islet cell antigens [25]. Using this assay, a remarkably high prevalence of islet peptide-specific IL-10-secreting T cells in HLA-matched healthy individuals was observed [25], consistent with the view that these cells may play a role in preventing disease development. Single cell cloning of these cells from healthy individuals has confirmed their regulatory potential [26]. IL-10-secreting T cells are also present in newly diagnosed patients with type 1 diabetes [25, 27, 28], but in contrast to healthy controls, a high frequency of IFN- $\gamma$-secreting (presumed proinflammatory) $\mathrm{T}$ cells is also present $[25,27]$, emphasising the potential importance of the balance between proinflammatory and Treg subsets. Interestingly, high frequencies of IL10-secreting $\mathrm{T}$ cells at diagnosis were associated with improved glycaemic control 3 months after diagnosis [28]. Since adult, antibody-negative first-degree relatives are at very low risk of disease even in the presence of a high level of genetic risk, we hypothesised that IL-10-secreting Tregs might play a role in this protection. Here we report the results of the first study of combined IFN- $\gamma$ (representing pro-inflammatory responses) and IL-10 (representing regulatory responses) islet-specific T cell assays in a large series of antibody-negative first-degree relatives compared with HLA-matched healthy controls and new-onset type 1 diabetes patients. 


\section{Methods}

Participants Young adult patients with newly diagnosed type 1 diabetes were identified from the South West Newly Diagnosed Diabetes Collection (SWENDIC), which covers a population of about 4 million and 14 hospitals in southwest England and south Wales. Type 1 diabetes was defined by American Diabetes Association criteria [29] and patients were diagnosed as having the disease by the local specialist diabetes team with an intention to start immediate insulin therapy. Participants who had a first-degree relative with type 1 diabetes but were themselves negative for circulating anti-islet autoantibodies, i.e. against GAD or tyrosine phosphatase-like insulinoma antigen 2 (IA-2), were identified through the UK (Bristol) Centre of the TrialNet Natural History Study [8]. HLA-matched healthy controls with no history of type 1 diabetes in their first-degree relatives were identified and recruited from staff and students of the University of Bristol, UK, and from the staff of University Hospitals Bristol NHS Foundation Trust (formerly United Bristol Healthcare Trust). Additional individuals were identified from local controls recruited for the TrialNet $\mathrm{T}$ cell Validation Study [30]

All participants were initially screened and selected for expression of the HLA restriction element, DRB $1^{*} 0401$, in DNA samples obtained either by mouth brush or venous blood sampling [31], as this is the restriction element used to derive the T cell epitope panel [25]. Positive participants then provided a sample $(70 \mathrm{ml})$ of venous blood for cytokine ELISPOT testing (see below) and measurement of autoantibodies against IA- 2 and GAD by immunoassay, as previously described [4]. Autoantibody titres were considered to be positive when their value was greater than the 97.5th percentile in a control population of 2860 healthy school children [4], i.e. $>6$ WHO Units for IA-2 and $>14$ WHO Units for GAD. Autoantibody assays were used to provide evidence of autoimmune diabetes in newly diagnosed type 1 diabetes patients and to exclude high risk of disease progression in first-degree relatives (associated with antibody positivity). Epitope correlations between B and T cell responses were not explored.

All human research procedures were performed with the approval of the Local Research Ethics Committee and with the written informed consent of all participants involved.

Peptide panel The peptide panel was derived from that used by Arif et al. [25] and included IA-2 and proinsulin peptides naturally processed and presented by HLA-DR4 (previously identified by Peakman et al. [32] and Arif et al. [25], respectively), as well as three 'promiscuous epitopes' from tetanus toxoid used as controls for the specificity of the $\mathrm{T}$ cell response $[25,33]$. Table 1 summarises the peptides used and their sequences. Amino acid sequences of peptides derived from the islet antigens IA-2 are given numbered from the amino terminus. For proinsulin, residue numbers are given in the C-peptide (number 6) or across the C-peptide-A chain junction (number 7). Tetanus toxoidderived peptides are given as single letter amino acid sequences, see Arif et al. [25] for further details. All the above peptides were synthesised to more than $90 \%$ purity using reverse-phase HPLC and mass spectrometry by Mimotopes (Clayton, VIC, Australia).

ELISPOT assay Cytokine ELISPOT assays were performed as previously described [25]. Peripheral blood mononuclear cells (PBMCs) were isolated from fresh blood samples within $4 \mathrm{~h}$ of venesection by buoyant density centrifugation $(580 \mathrm{~g}, 20 \mathrm{~min})$. PBMCs were then cultured in 48 -well plates at a density of $2 \times 10^{6}$ in $0.5 \mathrm{ml}$ RPMI- 1640 medium (Gibco, Invitrogen, Paisley, UK) supplemented with antibiotics (Antibiotic-Antimycotic; Gibco, Paisley, UK), 10\% (vol/vol.) human $A B$ serum (Harlan Sera-Lab, Loughborough, UK) and peptide to a final concentration of 10 to $20 \mu \mathrm{mol} / 1$, and incubated at $37^{\circ} \mathrm{C}, 5 \% \mathrm{CO}_{2}$, tilted by $5^{\circ}$. Wells containing culture medium plus either an equivalent amount of peptide diluent (DMSO) or 0.16 IU of tetanus toxoid (Diftavax; Aventis Pasteur MSD, Maidenhead, UK) were used as negative and positive assay controls, respectively. On day 1 after the above, $0.5 \mathrm{ml}$ pre-warmed tissue culture medium $/ 10 \%$ (vol./vol.) AB serum was added. The next day (day 2), non-adherent cells were resuspended using pre-warmed tissue culture medium $/ 2 \%$ (vol./vol.) AB serum, washed and brought to a concentration of $1 \times 10^{6}$, $300 \mu \mathrm{l}$, after which $100 \mu \mathrm{l}$ was dispensed in triplicate into wells of 96-well ELISA plates (Nunc Maxisorp; Merck, Poole, UK) pre-blocked with $1 \%$ (wt./wt.) BSA in PBS and pre-coated with monoclonal anti-IFN- $\gamma$ or anti-IL-10 capture antibody (U-Cytech, Utrecht, the Netherlands). After capture at $37^{\circ} \mathrm{C}, 5 \% \mathrm{CO}_{2}$ for $18 \mathrm{~h}$, plates were washed three times manually in PBS, followed by eight times in PBS/Tween 20 using an automated plate washer. Spots were then developed according to the manufacturer's instructions (U-Cytech). Plates were dried and spots of 80 to $120 \mu \mathrm{m}$ counted in a BioReader 4000 (BioSys, Karben, Germany). Background (non-specific) mean spot counts were low. For newly diagnosed type 1 diabetic patients, first-degree relatives and healthy controls groups respectively, mean background rates were $1.1,1.2$ and 1.7 spotforming cells $(\mathrm{SFC}) / 1 \times 10^{6} \mathrm{PBMC}$ for IFN- $\gamma$; and $0.8,1.5$ and $2.0 \mathrm{SFC} / 1 \times 10^{6}$ cells for IL-10.

ELISPOT analysis was performed strictly according to the following criteria. First, spots were counted as total number of spots per condition, summing all three wells and using customised settings in the BioReader (BioSys). Second, an assay was considered uninterpretable when the total number of spots for DMSO (negative assay control) 
Table 1 Sequences of peptide $\mathrm{T}$ cell epitopes used in the current study
PI, proinsulin; TT, tetanus toxoid

\begin{tabular}{|c|c|c|c|}
\hline \multicolumn{2}{|c|}{ Islet antigen-derived peptides } & \multicolumn{2}{|c|}{ Tetanus toxoid-derived peptides } \\
\hline Peptide & Residues & Peptide & Sequence \\
\hline IA-2 no. 1 & $652-680$ & TT no. 8 & NNFTVSWLRVPKVSAHLEQ \\
\hline IA-2 no. 2 & $709-736$ & TT no. 9 & RDIIDDFTNESSQKTT \\
\hline IA-2 no. 3 & $752-775$ & TT no. 10 & YIKANSKFIGITELK \\
\hline IA-2 no. 4 & $853-872$ & & \\
\hline IA-2 no. 5 & $955-976$ & & \\
\hline PI no. 6 & $\mathrm{C} 13-\mathrm{C} 32$ & & \\
\hline PI no. 7 & C19-A3 & & \\
\hline
\end{tabular}

was higher than a total of six spots in the three wells of the triplicate set $(4.3 \%$ of assays) or when it failed to show a positive response to tetanus toxoid and/or to tetanus toxoid epitopes for both cytokines ( $0.83 \%$ of assays); such assays were excluded from analysis. Third, a response was considered to be positive if the total number of spots was greater than the mean +2 SDs of all the negative control wells in participants of the same clinical group. To assess reproducibility, responses (either positive or negative) to the control peptide showing highest reactivity (and hence highest discriminative capacity, peptide 9) were compared on two occasions 3 to 24 months apart in a subsection consisting of 15 of 42 newly diagnosed type 1 diabetic patients, ten of 40 first-degree relatives and ten of 39 healthy controls. Across all 35 of these participants, 65\% agreement was observed for IFN- $\gamma$ and $68 \%$ for IL-10 responses on the two occasions, compared with an expected chance agreement rate of $50 \%$ and $55 \%$ respectively. These results equate to kappa statistic values of 0.29 for IFN- $\gamma$ and 0.28 for IL-10, which are consistent with those previously reported for similar T cell assays [30].

Statistics The frequency of positive peptide responses between the three groups was compared using a $\chi^{2}$ test with 2 degrees of freedom followed by post-hoc pairwise comparisons by $\chi^{2}$ testing, if the comparison of all three groups showed $p<0.05$. The size of positive responses was expressed as SFC $/ 1 \times 10^{6} \mathrm{PBMC}$ and the sum of positive responses (total SFC) in an individual to any peptide of the islet antigen peptide or tetanus toxoid panels was compared between the three participant groups by the Kruskal-Wallis test. At $p<0.05$ for this test, pairwise comparisons were made using the Mann-Whitney $U$ test. To examine the balance of regulatory and proinflammatory responses, we used the ratio of the maximal IL-10 response to any peptide in the panel divided by the maximal IFN- $\gamma$ response (both expressed as SFC/ $1 \times 10^{6} \mathrm{PBMC}$ after subtraction of negative assay control responses). Where the value for SFC was zero, the lowest measured value $(0.5)$ was substituted, as a ratio cannot be computed with a denominator of zero. To normalise the data, results were converted to the natural log of the ratio of IL-10: IFN- $\gamma$ SFC and compared using unpaired $t$ tests. The same approach was used to compare the total SFC with all islet or tetanus toxoid peptides between the groups.

\section{Results}

Table 2 summarises the characteristics of the participants studied. The mean ages of the groups were similar, but there were more males in the newly diagnosed type 1 diabetic patients group (as previously described for adultonset type 1 diabetes [34]). Of newly diagnosed patients, $83 \%$ were positive for autoantibodies to either IA-2 or GAD, again consistent with previous reports in this age group [34].

Frequency of IFN- $\gamma$-producing peptide responses Significant differences in the frequency of positive IFN- $\gamma$-producing responses to the peptide panel were seen between the three groups $(p=0.003)$ (Fig. 1a). In pairwise analysis, significantly more positive IFN- $\gamma$ responses were seen in the newly diagnosed type 1 diabetic patient group than in

Table 2 Characteristics of study participants

\begin{tabular}{llll}
\hline Variable & $\begin{array}{l}\text { Newly } \\
\text { diagnosed } \\
\text { T1D }\end{array}$ & $\begin{array}{l}\text { First-degree } \\
\text { relatives }\end{array}$ & $\begin{array}{l}\text { Healthy } \\
\text { controls }\end{array}$ \\
\hline$n$ & 42 & 40 & 39 \\
Age (years) & $28.5(15-41)$ & $32.9(13-47)$ & $28.2(19-50)$ \\
Male sex (\%) & 64 & 35 & 38 \\
$\begin{array}{c}\text { Positive for GAD or } \\
\text { IA-2 antibodies (\%) }\end{array}$ & 83.3 & $0^{\mathrm{a}}$ & $0^{\mathrm{b}}$ \\
$\begin{array}{c}\text { Disease duration } \\
\text { (months) }\end{array}$ & $7(0-24)$ & $\mathrm{NA}$ & $\mathrm{NA}$ \\
\hline
\end{tabular}

Values are mean (range) for age and median (range) for disease duration; all other values as indicated

${ }^{\text {a }}$ One IA-2 titre slightly over lower limit of 97.5 th percentile in control population; ${ }^{\mathrm{b}}$ one GAD titre slightly over lower limit of 97.5 th percentile in control population

NA, not applicable; T1D, type 1 diabetes 

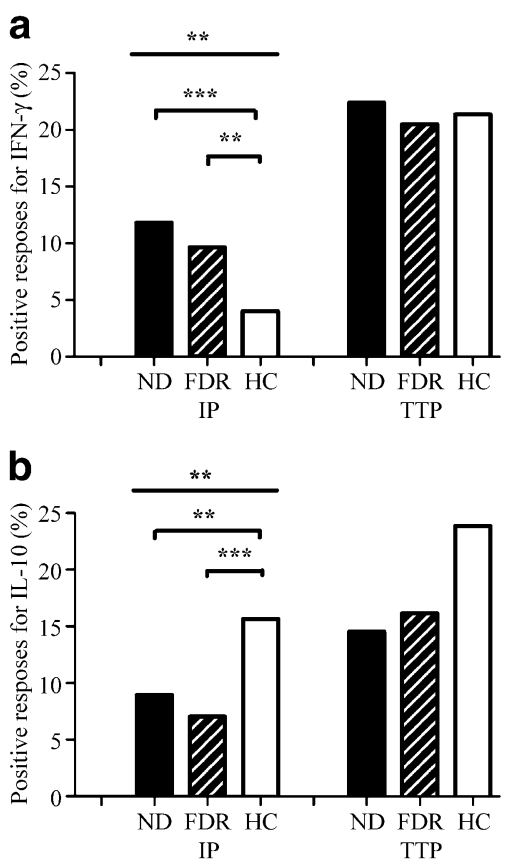

Fig. 1 Percentage of positive peptide responses for (a) IFN- $\gamma$ and (b) IL10 for the study groups newly diagnosed type 1 diabetic patients (ND), first-degree relatives (FDR) and healthy controls (HC). Each individual was tested against the islet peptide panel (IP, seven peptides) and the tetanus toxoid panel (TTP, three peptides). Number of positive peptide responses per total number tested: (a) IP ND 34/287, IP FDR 27/279, IP HC 11/273, TTP ND 29/122, TTP FDR 25/117, TTP HC 26/117; (b) IP ND 26/287, IP FDR 20/280, IP HC 43/273, TTP ND 18/123, TTP FDR 19/117, TTP HC $28 / 117 .{ }^{* *} p<0.01,{ }^{* * *} p<0.001$ for difference in responses within study groups

healthy controls $(p=0.0003)$ as expected. Interestingly, the first-degree relatives group also had significantly more peptide responses than the healthy controls $(p=0.009)$, suggesting they had a degree of proinflammatory disease activity, despite being at very low risk of developing clinical diabetes. There was no significant difference in frequency of peptide responses between the first-degree relatives and the type 1 diabetes group. For individuals with a positive response, the median number of peptides recognised was similar between the groups $(1.5,1.5$ and 1.0 for diabetic patients, relatives and healthy controls respectively) All participant groups showed a similar frequency of IFN- $\gamma$ responses to the tetanus toxoid panel $(p=0.9)$ (Fig. 1a).

Frequency of IL-10-secreting peptide responses Significant between-group differences were also seen in the frequency of positive IL-10-producing responses to the peptide panel $(p=0.003)$ (Fig. 1b), but in the opposite direction to the IFN- $\gamma$ responses (Fig. 1a). In pairwise analysis, the frequency of responses was higher in healthy controls than in both newly diagnosed type 1 diabetic patients $(p=0.008)$ and first-degree relatives $(p=0.007)$. For individuals with a positive IL-10 response, the median number of peptides recognised was similar between the groups (1.5, 2.0 and 2.0 for diabetic patients, relatives and healthy controls respectively). When all three groups were compared, no significant difference in IL-10 responses to control (tetanus toxoid) peptides was seen, although there was a trend to more frequent responses in the control group $(p=0.14)$, suggestive of a general tendency towards less regulatory responses in participants from affected families.

Size of peptide responses As a measure of the magnitude of $\mathrm{T}$ cell response, Fig. 2 compares the total number of islet peptide-specific SFC in a given individual with that of individuals showing a positive response to one or more peptides in the other groups. The total number of SFC in positive IFN- $\gamma$ responses was similar in size between the groups (around $10 \mathrm{SFC} / 1 \times 10^{6} \mathrm{PBMC}$ ) (Fig. 2a). By contrast, the total SFC in positive IL-10 responses was around three times greater than the IFN- $\gamma$ responses and significantly larger in first-degree relatives $(p=0.02)$ and healthy controls groups $(p=0.008)$ than in the type 1 diabetic patients, with total IL-10 responses in diabetic patients, first-degree relatives and healthy controls of 11 (3.5-24), 29 (12.5-53) and $33(14-115) \mathrm{SFC} / 1 \times 10^{6} \mathrm{PBMC}$ respectively (Fig. 2b). No difference was seen in the median total SFC of positive tetanus toxoid peptide responses between groups (Fig. 2c, d).

Frequency of individual peptide responses Figures 3 and 4 examine the individual positive peptide responses further. Figure 3 shows the frequency of positive responses to the three different tetanus toxoid peptides (numbers 8-10) studied and illustrates that peptide number 9 was the most commonly and peptide number 8 the least commonly recognised peptide. This was true for all three groups of participants, and for IFN- $\gamma$ and IL-10 responses. Figure 4 compares the frequency of positive peptide responses to each islet peptide with that of the least commonly recognised tetanus toxoid peptide, peptide number 8 . Here, peptide number 8 is being used as a surrogate 'negative peptide' to determine whether the response frequencies to individual islet peptides are any higher than the expected background level of immune response to any irrelevant or random peptide. It is not possible to have a true 'negative peptide' as any randomly generated sequence may in fact be part of an epitope from an unknown foreign or selfpeptide. The use of the response to peptide number 8 as a surrogate 'negative peptide' represents quite a stringent test, as responses to this tetanus toxoid-derived sequence would, if anything, be expected to be higher than background.

Gradations in opposite directions for the two cytokines can be seen in Fig. 4. For IFN- $\gamma$, seven of seven islet peptides in newly diagnosed type 1 diabetic patients, five of seven in first-degree relatives and only one of seven in 
Fig. 2 Size of responses: total $\mathrm{SFC} / 1 \times 10^{6} \mathrm{PBMC}$ for positive

IFN- $\gamma$ and IL-10 peptide responses to the islet antigen peptide panel and the tetanus toxoid (TT) peptide panel for the participant groups newly diagnosed type 1 diabetic patients (ND), first-degree relatives (FDR) and healthy controls (HC). a IFN- $\gamma$ islet antigen peptide panel, (b) IL-10 islet antigen peptide panel, (c) IFN- $\gamma$ TTP and (d) IL-10 TTP. Data, expressed as the number of SFC per million PBMC $\left(\mathrm{SFC} / 1 \times 10^{6}\right.$ PBMC), are shown for all individuals who had a positive peptide response. Horizontal bars represent median values. Comparisons were made using non-parametric statistics and outlying values were checked by two observers. ${ }^{*} p<0.05$, ${ }^{* * *}<0.01$ for difference in maximal response between study groups a

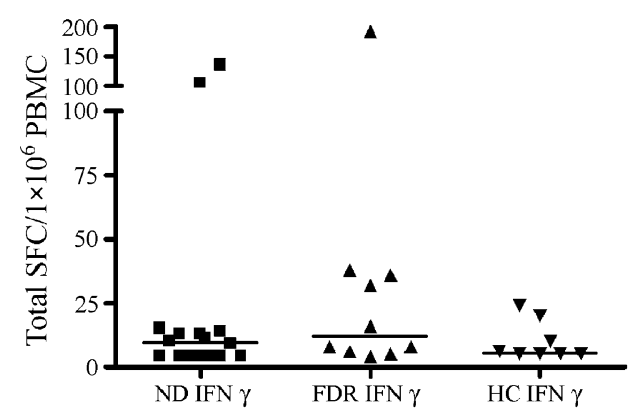

C

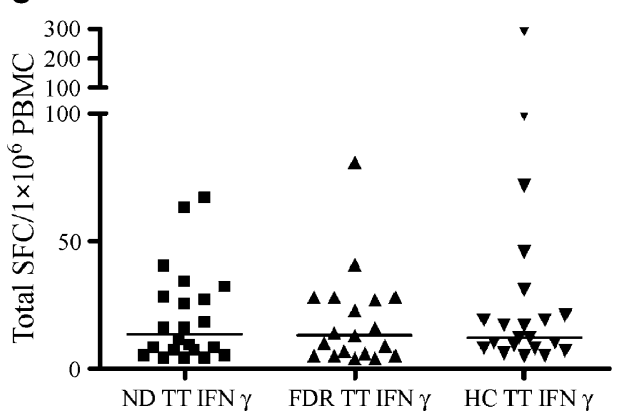

b

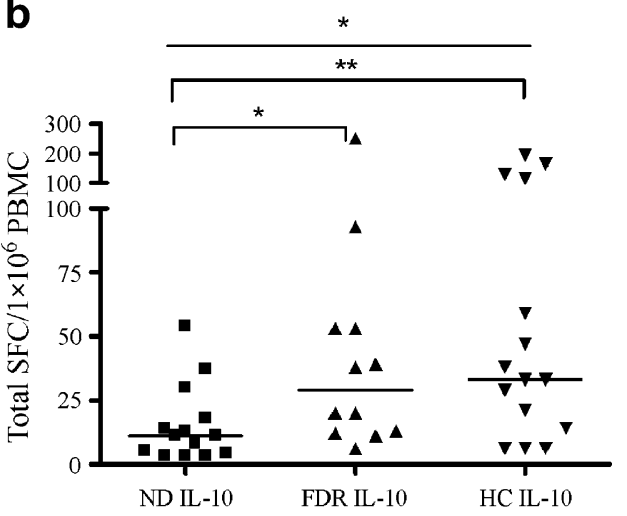

d

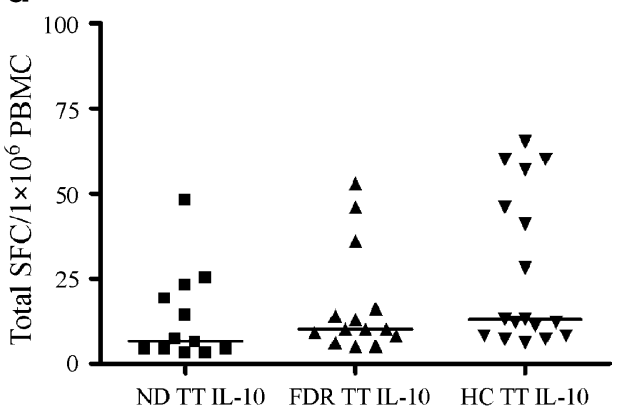

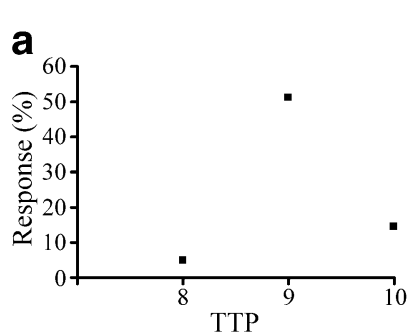

C

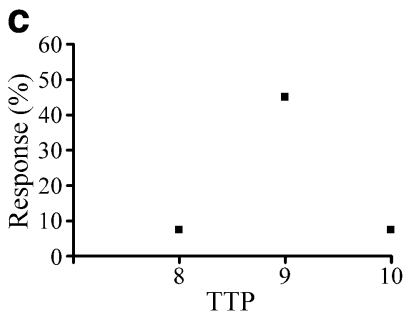

e

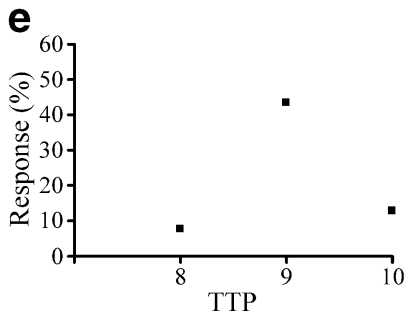

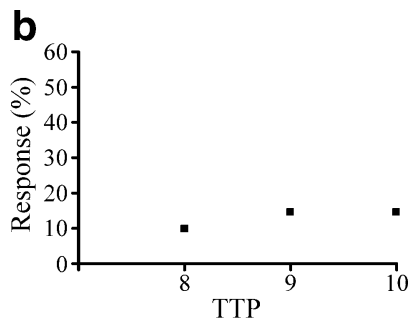

d
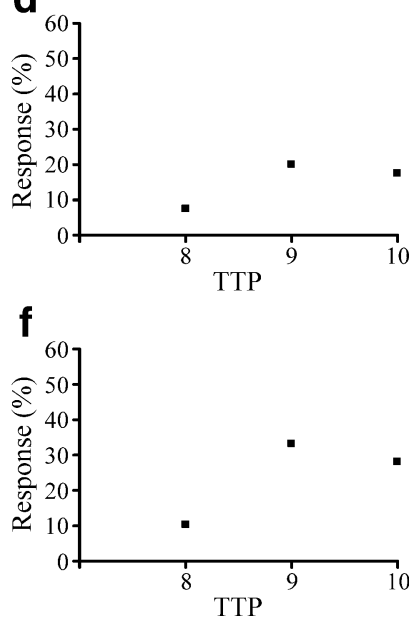

Fig. 3 Frequency of positive responses to individual tetanus toxoid peptides (TTP). a IFN- $\gamma$ and (b) IL-10 in newly diagnosed type 1 diabetic patients; (c) IFN- $\gamma$ and (d) IL-10 in first-degree relatives; (e) IFN- $\gamma$ and (f) IL-10 in healthy controls. Results represent the percentage of all tests that were positive for the individual tetanus toxoid peptides shown. See Table 1 for peptide sequences

healthy controls had responses equal to or greater than peptide number 8 . Conversely, for IL-10, three of seven, five of seven and seven of seven peptides for diabetic patients, relatives and controls respectively had responses equal to or greater than peptide number 8 .

It should also be noted that no single 'dominant' islet peptide from the panel can be identified as the 'best responder' across all groups, either for both cytokines together, or for each individual cytokine. This emphasises that individual peptide responses represent just a small sample of all the responses to a group of antigens; it also underlines the need for as broad a panel of peptides as possible to reflect the nature of the overall autoimmune response.

Balance between IL-10- and IFN- $\gamma$-producing $T$ cell responses The overall $\mathrm{T}$ cell response is likely to be a balance of the regulatory and pro-inflammatory $\mathrm{T}$ cell responses. To reflect this, the ratio of maximal IL-10 response to maximal IFN- $\gamma$ response was computed in each individual. Figure 5 a compares the mean values of this ratio between the disease activity groups, showing that the healthy controls group had a significantly greater IL-10: IFN- $\gamma$ ratio among islet-peptide responses than the newly diagnosed type 1 diabetes group ( $p=0.03$ ) (Fig. 5a). Values for first-degree relatives were intermediary between the diabetic patients and healthy controls $(p=0.09$ for the trend across all three groups). No differences in the ratios in 
a

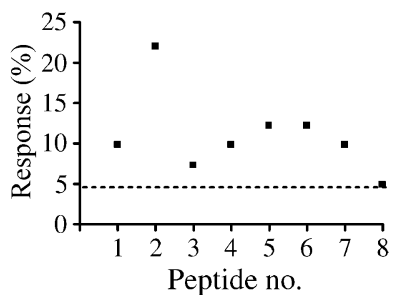

C

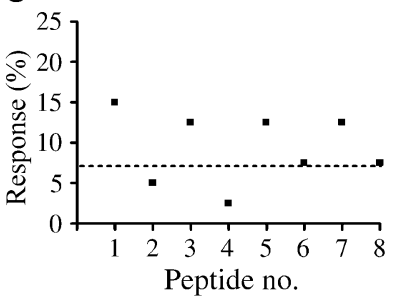

e

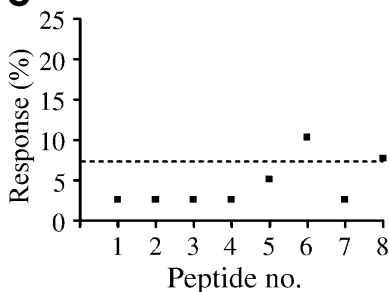

b

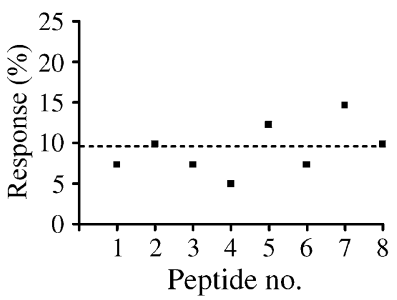

d

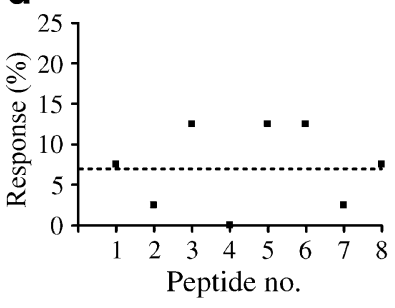

f

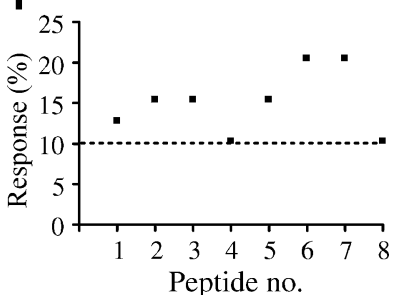

Fig. 4 Frequency of positive responses to individual islet antigen peptides compared with that to the low responder tetanus toxoid peptide number 8. a IFN- $\gamma$ and (b) IL-10 in newly diagnosed type 1 diabetic patients; (c) IFN- $\gamma$ and (d) IL-10 in first-degree relatives; (e) IFN- $\gamma$ and (f) IL-10 in healthy controls. Results represent the percentage of all tests that were positive for the islet antigen peptides shown. See Table 1 for peptide sequences. Dotted line, frequency of positive responses to peptide number 8 in this group of participants for the cytokine indicated

responses to control (tetanus toxoid) peptides were seen ( $p=0.47$ for the trend across all three groups) (Fig. $5 b$ ). Note that the mean log ratios were negative for tetanus toxoid responses in all groups, indicating a predominant IFN- $\gamma$ response (ratio IL-10:IFN- $\gamma$ SFC $<1$ ) (Fig. 5b), whereas for islet peptide responses in first-degree relatives and healthy controls the mean ratio was positive (Fig. 5a) and indicated a predominant IL-10 response. Maximal responses were compared, as the majority of individuals responded to only one or two peptides of the panel. However, a trend in the same direction was also seen, when total SFC to all islet or tetanus toxoid peptides were compared (Fig. 5c, d).

No significant correlations were seen between the size or frequency of peptide responses and the age of participants or, in the case of newly diagnosed type 1 diabetic patients, disease duration or antibody positivity.

\section{Discussion}

The results reported here show clear differences in the frequency and size of IFN- $\gamma$ vs IL-10-secreting islet

antigen-specific $\mathrm{T}$ cell responses between the clinical groups studied, with antibody-negative first-degree relatives appearing to show a phenotype intermediate between newly diagnosed type 1 diabetic patients and healthy controls. For the proinflammatory cytokine, IFN- $\gamma$, responses to the peptide panel were similar in frequency in the patients and first-degree relatives groups, but significantly more frequent than in healthy controls (diabetic patients vs healthy controls $p=0.0003$, relatives vs healthy controls $p=0.009$; Fig. 1a). The importance of the breadth of IFN- $\gamma$ responses across the peptide panel is emphasised by the observation that the frequency of positive responses to all seven islet peptides in the panel was greater than expected for an irrelevant peptide in newly diagnosed type 1 diabetic patients (tetanus toxoid peptide number 8), whereas this was only true for one of seven peptides for healthy controls. An intermediate result was seen for first-degree relatives, with five of seven peptides of the panel showing an increased frequency response greater than peptide 8 (Fig. 4). The maximal size of IFN- $\gamma$-secreting positive islet peptide responses was relatively modest, being smaller than that seen for tetanus toxoid peptides, and did not differ between the clinical groups (Fig. 2).

By contrast, potential Treg (IL-10) responses to the peptide panel showed the opposite pattern. The frequency of positive peptide responses was greater in healthy controls than in newly diagnosed type 1 diabetic patients $(p=0.008)$. First-degree relatives showed a frequency
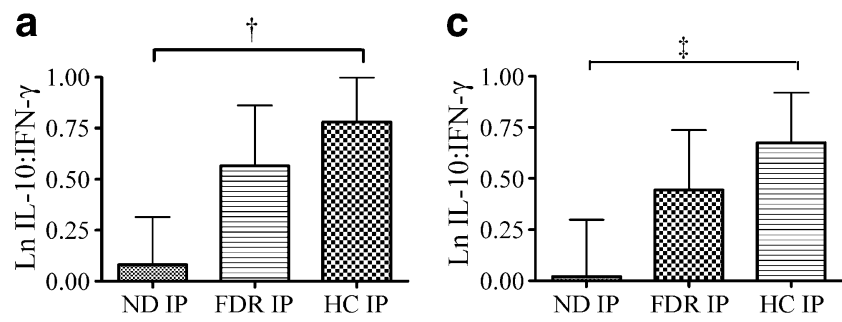

b
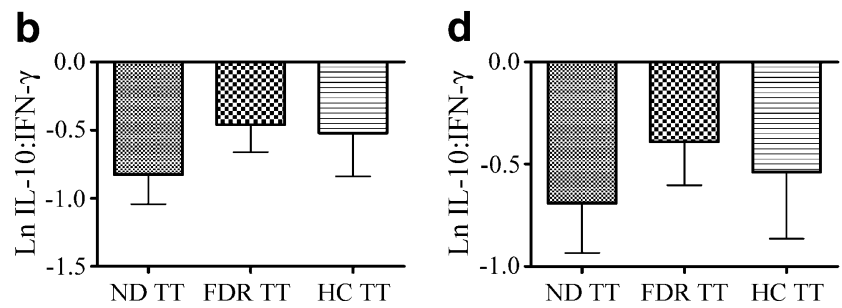

Fig. 5 Comparison of the ratio of IL-10:IFN- $\gamma$ SFC/ $1 \times 10^{6}$ PBMC between participant groups newly diagnosed type 1 diabetic patients (ND), first-degree relatives (FDR) and healthy controls (HC). Comparison is shown of the maximum peptide responses to (a) the islet peptide panel (IP) and (b) the tetanus toxoid peptide panel (TTP). c Total SFC responses to all peptides of the islet panel and (d) all peptides of the tetanus toxoid peptide panel. Note that data on all participants were included in this latter analysis (panels $\mathbf{c}$ and $\mathbf{d}$ ), irrespective of whether individual responses met criteria for positivity. Results are expressed as the natural $\log$ of the ratio. ${ }^{\dagger} p=0.03 ;{ }^{\star} p=0.08$ 
similar to that in the diabetic patients group and significantly less than that in healthy controls $(p=0.0007)$ (Fig. 1b). However, the size (measured in total $\mathrm{SFC} / 1 \times$ $10^{6}$ PBMC) of positive peptide responses in first-degree relatives was similar to that in healthy controls $(p=0.8)$ and both were significantly greater than that in newly diagnosed type 1 diabetic patients (relatives vs diabetic patients $p=0.02$; healthy controls vs diabetic patients $p=0.008$ ) (Fig. 2). Furthermore, in healthy controls, seven of seven islet peptides showed an IL-10 response more frequently than the weakest tetanus toxoid peptide as compared with five of seven in first-degree relatives and only one of seven in newly diagnosed type 1 diabetic patients (Fig. 4). In contrast with IFN- $\gamma$, the overall magnitude of islet peptide responses was similar (diabetic patients) or very much greater (relatives and healthy controls) than the size of responses to tetanus toxoid peptides (Fig. 2). There was a non-significant trend to generally higher IL-10 responses in healthy controls than in the other groups (as shown by comparison of tetanus toxoid responses, $p=0.14$ ) (Fig. 1b). However, at best this can only partially explain the differences seen, as no such difference was observed in the first-degree relatives group. In addition, no trend to greater IL-10 production in healthy controls was observed in a previous study using non-specific mitogenic stimulation of $\mathrm{T}$ cells [35]. Taken together, these results indicate that although antibody-negative first-degree relatives have IFN- $\gamma$ responses to islet peptide almost as frequently as newly diagnosed type 1 diabetic patients, they are potentially protected by individual IL-10 responses that are very much larger than in newly diagnosed type 1 diabetic patients and comparable to those seen in healthy controls. When the ratio of maximal IL-10 and IFN- $\gamma$ responses computed for each individual is compared between the groups, the response of first-degree relatives is intermediate between diabetic patients and healthy controls (Fig. 5).

Antibody-negative first-degree relatives are characterised by a very low rate of progression to diabetes, despite sharing $50 \%$ of the genetic risk and a large part of the environmental risk of their affected siblings. Hence in our original hypothesis, we speculated that they would be 'super-protected' and have a greater Treg response than healthy controls. However, we found that their response is intermediate between that of healthy controls and newly diagnosed type 1 diabetic patients, and that they have a not insignificant frequency of pro-inflammatory responses. This finding is interesting, for if the responses studied here are truly representative of the overall immune response to the islet, this would suggest that: (1) even a modest amount of regulatory activity may be sufficient to prevent disease developing over the lifetime of an individual; and (2) the very high degree of protection present in healthy controls is more than is required. Such a finding provides considerable reassurance for immunotherapeutic approaches aimed at amplifying the islet antigen-specific Treg response [2, 36].

This is the first study of antigen-specific T cell reactivity in antibody-negative first-degree relatives. The IFN- $\gamma$ ELISPOT results observed by us in newly diagnosed type 1 diabetic patients and healthy controls are consistent with previous reports studying peptide libraries from insulin and IA-2 [25, 37-39]. In all cases, a broad range of epitopes was recognised and more frequently in newly diagnosed type 1 diabetic patients than in healthy controls. For IL-10, there have only been two other previous reports $[27,28]$ besides our own [25] of antigen-specific $\mathrm{T}$ cell responses in type 1 diabetes. The study of Sanda and colleagues showed the presence of IL-10-secreting cells recognising a broad spectrum of epitopes in newly diagnosed children, but did not include a healthy control group [28]. In the study by Durinovic-Bello and colleagues [27], no difference in the frequency of responses between newly diagnosed type 1 diabetic patients and healthy controls was seen when whole PBMC were tested by ELISPOT. However, among the memory T cell subset, IL-10 responses were more frequent in high-risk (antibody-positive) relatives and newly diagnosed participants than in HLA-matched control participants. This contrasts with the findings of the current and previous studies from our group [25] and the differences remain unexplained. The overall frequency of responses in the current study is low compared with earlier studies, although many of these used a larger peptide panel or whole antigen and hence are likely to have detected a larger proportion of the islet-specific $\mathrm{T}$ cell response, which all studies have shown to be very heterogeneous. The present results emphasise the requirement for a broad peptide panel in such studies where peptides rather than whole antigen are used. Finally, we cannot be certain of the true phenotypic behaviour of the T cell subsets studied, for example whether IL-10-secreting cells are indeed Tregs, but the distribution between patient groups certainly suggests this. Further in vitro studies of $T$ cell subsets employing functional regulatory assays are required for confirmation.

In conclusion, our study indicates that antibody-negative first-degree relatives have proinflammatory islet-specific $\mathrm{T}$ cell responses similar in frequency to those in newly diagnosed type 1 diabetic patients, but this appears to be counterbalanced by some large IL-10 responses to individual epitopes. If these findings are confirmed in future studies using other peptide panels, they suggest that ELISPOT detection of IL-10 responses would be a useful measure of specific Treg activity in type 1 diabetes. They also indicate that if immunointerventions can effect even a modest increase in this activity, this increase (assuming it is not overwhelmed by a concomitant increase in pro- 
inflammatory cells) could result in significant preservation of beta cell function.

Acknowledgements We are grateful to M. Peakman, S. Arif and C. Van Krinks for advice on the cytokine ELISPOT assay and to P. Bingley, K. Gillespie, A. Williams and R. Aitken for autoantibody assays and HLA typing, as well as recruitment of antibody-negative first-degree relatives with support from H. Castledon, N. Farthing and R. Elliott-Jones. Thanks also to the Bristol centre of Diabetes TrialNet which provided subjects for the first-degree relative and healthy control groups from the Natural History Study and the $\mathrm{T}$ cell Validation Study. We are also grateful to the diabetes teams at Bristol Royal Infirmary, Southmead and Frenchay Hospitals (Bristol), as well as the hospitals in Weston-super-Mare, Bath, Gloucester, Cheltenham, Abergavenny, Cardiff, Newport, Swansea, Taunton and Yeovil for identifying newly diagnosed participants. This work was generously supported by The Sir Jules Thorn Charitable Trust. Part of this work was presented as an oral presentation and published as an abstract at the British Society for Immunology Congress 2007 (SECC, Glasgow, 20-23 February), as well as shown as a poster and published as an abstract at the 9th International Congress of the Immunology of Diabetes Society and the American Diabetes Association Research Symposium (Miami Beach, FL, USA, 14-18 November 2007).

Duality of interest The authors declare that there is no duality of interest associated with this manuscript.

\section{References}

1. Achenbach P, Bonifacio E, Koczwara K, Ziegler AG (2005) Natural history of type 1 diabetes. Diabetes 54(Suppl 2):S25-S31

2. Pozzilli P (2007) Immuno-intervention and preservation of beta-cell function in type 1 diabetes. Diabetes Metab Res Rev 23:255-256

3. Achenbach P, Bonifacio E, Ziegler AG (2005) Predicting type 1 diabetes. Curr Diab Rep 5:98-103

4. Bingley PJ, Bonifacio E, Williams AJ, Genovese S, Bottazzo GF, Gale EA (1997) Prediction of IDDM in the general population: strategies based on combinations of autoantibody markers. Diabetes 46:1701-1710

5. Bingley PJ, Bonifacio E, Ziegler AG, Schatz DA, Atkinson MA, Eisenbarth GS (2001) Proposed guidelines on screening for risk of type 1 diabetes. Diabetes Care 24:398

6. Gardner SG, Gale EA, Williams AJ et al (1999) Progression to diabetes in relatives with islet autoantibodies. Is it inevitable? Diabetes Care 22:2049-2054

7. Verge CF, Gianani R, Kawasaki E et al (1996) Prediction of type I diabetes in first-degree relatives using a combination of insulin, GAD, and ICA512bdc/IA-2 autoantibodies. Diabetes 45:926-933

8. Mahon JL, Sosenko JM, Rafkin-Mervis L et al (2008) The TrialNet natural history study of the development of type 1 diabetes: objectives, design, and initial results. Pediatr Diabetes 10:97-104

9. Redondo MJ, Rewers M, Yu L et al (1999) Genetic determination of islet cell autoimmunity in monozygotic twin, dizygotic twin, and non-twin siblings of patients with type 1 diabetes: prospective twin study. BMJ 318:698-702

10. Roep BO (2003) The role of T-cells in the pathogenesis of type 1 diabetes: from cause to cure. Diabetologia 46:305-321

11. Wong FS, Dayan CM (2008) Regulatory T cells in autoimmune endocrine diseases. Trends Endocrinol Metab 19:292-299

12. Pop SM, Wong CP, Culton DA, Clarke SH, Tisch R (2005) Single cell analysis shows decreasing FoxP3 and TGFbetal coexpressing
$\mathrm{CD} 4+\mathrm{CD} 25+$ regulatory $\mathrm{T}$ cells during autoimmune diabetes. $\mathrm{J}$ Exp Med 201:1333-1346

13. Tritt M, Sgouroudis E, d'Hennezel E, Albanese A, Piccirillo CA (2008) Functional waning of naturally occurring CD4+ regulatory T-cells contributes to the onset of autoimmune diabetes. Diabetes 57:113-123

14. Wildin RS, Smyk-Pearson S, Filipovich AH (2002) Clinical and molecular features of the immunodysregulation, polyendocrinopathy, enteropathy, X linked (IPEX) syndrome. J Med Genet 39:537-545

15. Kukreja A, Cost G, Marker J et al (2002) Multiple immunoregulatory defects in type-1 diabetes. J Clin Invest 109:131-140

16. Brusko TM, Wasserfall $\mathrm{CH}$, Clare-Salzler MJ, Schatz DA, Atkinson MA (2005) Functional defects and the influence of age on the frequency of CD4+ CD25+ T-cells in type 1 diabetes. Diabetes 54:1407-1414

17. Tree TI, Roep BO, Peakman M (2006) A mini meta-analysis of studies on $\mathrm{CD} 4+\mathrm{CD} 25+\mathrm{T}$ cells in human type 1 diabetes: report of the Immunology of Diabetes Society T Cell Workshop. Ann N Y Acad Sci 1079:9-18

18. Lindley S, Dayan CM, Bishop A, Roep BO, Peakman M, Tree TI (2005) Defective suppressor function in CD4(+)CD25(+) T-cells from patients with type 1 diabetes. Diabetes 54:92-99

19. Jonson CO, Hedman M, Karlsson Faresjo M et al (2006) The association of CTLA-4 and HLA class II autoimmune risk genotype with regulatory $\mathrm{T}$ cell marker expression in 5-year-old children. Clin Exp Immunol 145:48-55

20. Shoda LK, Young DL, Ramanujan S et al (2005) A comprehensive review of interventions in the NOD mouse and implications for translation. Immunity 23:115-126

21. Wraith DC (2003) Role of interleukin-10 in the induction and function of natural and antigen-induced regulatory $\mathrm{T}$ cells. $\mathrm{J}$ Autoimmun 20:273-275

22. Raz I, Elias D, Avron A, Tamir M, Metzger M, Cohen IR (2001) Beta-cell function in new-onset type 1 diabetes and immunomodulation with a heat-shock protein peptide (DiaPep277): a randomised, double-blind, phase II trial. Lancet 358:1749-1753

23. Herold KC, Burton JB, Francois F, Poumian-Ruiz E, Glandt M, Bluestone JA (2003) Activation of human $\mathrm{T}$ cells by FcR nonbinding anti-CD3 mAb, hOKT3gamma1(Ala-Ala). J Clin Invest 111:409-418

24. Di Lorenzo TP, Peakman M, Roep BO (2007) Translational minireview series on type 1 diabetes: systematic analysis of $\mathrm{T}$ cell epitopes in autoimmune diabetes. Clin Exp Immunol 148:1-16

25. Arif S, Tree TI, Astill TP et al (2004) Autoreactive T cell responses show proinflammatory polarization in diabetes but a regulatory phenotype in health. J Clin Invest 113:451-463

26. Tree TI, Lawson J, Edwards $H$ et al (2010). Naturally arising human CD4 $\mathrm{T}$ cells that recognize islet autoantigens and secrete IL-10 regulate pro-inflammatory $\mathrm{T}$ cell responses via linked suppression. Diabetes. doi:10.2337/d609-0503

27. Durinovic-Bello I, Schlosser M, Riedl M et al (2004) Pro- and anti-inflammatory cytokine production by autoimmune $\mathrm{T}$ cells against preproinsulin in $H L A-D R B 1^{*} 04, D Q 8$ type 1 diabetes. Diabetologia 47:439-450

28. Sanda S, Roep BO, von Herrath M (2008) Islet antigen specific IL-10+ immune responses but not CD4+CD25+FoxP3+ cells at diagnosis predict glycemic control in type 1 diabetes. Clin Immunol 127:138-143

29. American Diabetes Association (2008) Standards of medical care in diabetes-2008. Diabetes Care 31(Suppl 1):S12-S54

30. Herold KC, Brooks-Worrell B, Palmer J et al (2009) Validity and reproducibility of measurement of islet autoreactivity by T-cell assays in subjects with early type 1 diabetes. Diabetes 58:2588 2595 
31. Gillespie KM, Valovin SJ, Saunby J et al (2000) HLA class II typing of whole genome amplified mouth swab DNA. Tissue Antigens 56:530-538

32. Peakman M, Stevens EJ, Lohmann T et al (1999) Naturally processed and presented epitopes of the islet cell autoantigen IA-2 eluted from HLA-DR4. J Clin Invest 104:1449-1457

33. Panina-Bordignon P, Tan A, Termijtelen A, Demotz S, Corradin G, Lanzavecchia A (1989) Universally immunogenic T cell epitopes: promiscuous binding to human MHC class II and promiscuous recognition by T cells. Eur J Immunol 19:22372242

34. Ostman J, Lonnberg G, Arnqvist HJ et al (2008) Gender differences and temporal variation in the incidence of type 1 diabetes: results of 8012 cases in the nationwide Diabetes Incidence Study in Sweden 1983-2002. J Intern Med 263:386394
35. Rapoport MJ, Bistritzer T, Aharoni D et al (2005) TH1/TH2 cytokine secretion of first degree relatives of T1DM patients. Cytokine 30:219-227

36. Peakman M, Dayan CM (2001) Antigen-specific immunotherapy for autoimmune disease: fighting fire with fire? Immunology 104:361-366

37. Higashide T, Kawamura T, Nagata $M$ et al (2006) T cell epitope mapping study with insulin overlapping peptides using ELISPOT assay in Japanese children and adolescents with type 1 diabetes. Pediatr Res 59:445-450

38. Herzog BA, Ott PA, Dittrich MT et al (2004) Increased in vivo frequency of IA-2 peptide-reactive IFNgamma+/IL-4- T cells in type 1 diabetic subjects. J Autoimmun 23:45-54

39. Ott PA, Dittrich MT, Herzog BA et al (2004) T cells recognize multiple GAD65 and proinsulin epitopes in human type 1 diabetes, suggesting determinant spreading. J Clin Immunol 24:327-339 